\title{
INNOVATIVE CLUSTERS OF BUSINESS ACCELERATORS IN THE SPHERE OF SCIENCE AND TECHNOLOGY ENTREPRENEURSHIP
}

\author{
Mykhailo Ryabokon', Yurii Pikalov²
}

\begin{abstract}
In a broad sense, the author's study was preconditioned by the problem of arranging the efficient system for positioning of the enterprises of venture entrepreneurship acceleration and incubation that today is quite a controversial aspect. At the same time, for today there are no studies and publications related to the identification of approaches to the positioning of clusters of the enterprise innovative activity acceleration that will make it possible to find the most efficient approaches to acceleration. Therefore, this paper is aimed at identifying the basic approaches in the positioning of startup acceleration and incubation institutes. Methodology. The study is based on the algorithms of cluster analysis. Having identified the key parameters of the analysed institutions, using the "Statistics7" program package, we have combined the input data to address the challenge of cluster analysis, consisting in classification breakdown, which meets the criterion of optimality. Proceeding from the research target, the rule "Single Linkage" was chosen as the key function. According to this rule, there are two objects, being the closest to each other. At the next step, the object, which has the maximum degree of similarity with one of the cluster objects, joins them. This method is also called the method of the closest neighbour as the distance between two clusters is defined as the distance between the closest two objects in different clusters. 1 - Pearson is chosen as a degree of distance as far as the given data cannot be presented as points in k-dimensional space. Results. The first part of this research contains a justification of the positioning indicators among the analysed startup accelerators, which were chosen for cluster analysis according to functioning models. In the second part, we consider the distinction of the functioning models of the obtained clusters and the features, typical for every enterprise, which has been involved in the study. Proceeding from the calculation of the configuration of distances of cluster formations using the method of k-means while approaching the process of startup acceleration and incubation, we have identified the aspect, which is of primary importance for the formation of resultative startup-accelerator. Practical implications. The obtained results make it possible to optimize the resources in the process of creation and positioning of startup accelerators and incubators. Value/originality. Based on the developed configuration of the distances of cluster formations using the method of k-means in approached-to-startup acceleration and incubation process, we have found out the best practices in the area of venture business acceleration.
\end{abstract}

Key words: indicators, system parameters, positioning, capitalization, enterprise, acceleration, science and technology entrepreneurship, incubation.

\section{JEL Classification: M13, L60}

\section{Introduction}

Modern stage of global development is involved in globalization processes, characterized by enhancement of innovative activity in all spheres, as well as harnessing high technology and manufacturing innovative scienceintensive products, which are the key factors of steady economic growth for the majority of the developed countries of the world. At the same time, it seems clear that the innovative economy cannot be built without an active development of enterprises, conducting research

\footnotetext{
Corresponding author:

${ }^{1}$ Non-Governmental Organization “Noosphere”, Ukraine.

E-mail: aegladchenko@i.ua

${ }^{2}$ Cherkasy State Technological University, Ukraine.

E-mail: aegladchenko@i.ua
}

and development activities. Within the framework of forming the innovative structure, such institutions as a business incubator, technopark, technopolis, engineering school, high-tech centres, etc. have been developed and focused on creating favourable conditions for innovative activities, support and development of small-scale innovative entrepreneurship.

The above-mentioned forms of scientific and technological business are a system that integrates science, education, and production. It is an essential infrastructure 
element of national innovative systems, which promotes the formation of an innovative economy by the way of: development of science-intensive technologies and enterprises; selection and support of the promising scientific projects; commercialization of research findings and scientific and technological developments; rendering various services to small business entities, primarily, related to development of firms in the startup phase, etc. At the same time, today we have a relative dispersion of organization forms of such kind of activities. Thus, a justification of the axiomatics of the elements of venture entrepreneurship efficiency is of particular interest. A study of different aspects of entrepreneurship formation and development in terms of the innovative infrastructure is contained in the following papers: G. N. Ganamotse, M. Samuelsson, R. M. Abankwah, T. Anthony, T. Mphela (2017); D. Dellermann, N. Lipusch, P. Ebel, J.M. Leimeister (2017). A study of the innovative practice of business incubation, which allows the identification of management specifics in different countries, is contained in the following works: C. M. DaSilva, P. Gurtner (2017, January), J. Gonzalez-Uribe, M. Leatherbee (2017), S. Shane, N. Nicolaou (2017). At the same time, for today there are no studies and publications related to the identification of approaches to the positioning of clusters of the enterprise innovative activity acceleration that will make it possible to find the most efficient approaches to acceleration. Therefore, this study is aimed at the identification of the best practices of international science and technology business functioning based on a calculation of clusters.

\section{Methodological approach}

Having identified the key parameters of the analysed institutions, using the "Statistics7" program package, we have combined the input data to address the challenge of cluster analysis, consisting in classification breakdown, which meets the criterion of optimality. Proceeding from the research target, the rule "Single Linkage" was chosen as the key function. According to this rule, two objects, being the closest to each other, i.e. which have the maximum degree of similarity, are combined at the first step. At the next step the object, which has the maximum degree of similarity with one of the cluster objects, joins them. This method is also called the method of the closest neighbour as the distance between two clusters is defined as the distance between the closest two objects in different clusters. 1 - Pearson (1 minus coefficient of Pearson's correlation) was chosen as a degree of distance as far as the given data cannot be presented as points in k-dimensional space. When addressing a huge amount of problems in economics or sociology, the objects can be presented as points in k-dimensional space. In this case, it is expedient to use 1 - Pearson (1 minus coefficient of Pearson's correlation).

\section{Conducting research and results}

In order to conduct cluster analysis we have selected 19 institutions in the sphere of acceleration of the innovative activity and the following indicators, which are basic characteristics of their functioning: initial investment *thousand dollars); share in the project (\%); total number of projects, registered in 2017; number of successful projects; amount of time to be spent on acceleration; time period of incubation program; capitalization (million dollars); number of sectoral areas under consideration.

Thus, the first indicator, which is of utmost importance while defining the effectiveness of building the accelerating institutions, is the amount of initial investment. Among the largest and the most popular institutions of similar format, which were selected for this study, their distribution is quite uneven. Therefore, this aspect is of utmost importance.

The next aspect of the positioning of the institution in the sphere of startup acceleration and incubation is represented by dynamics of the number of registered projects and the number of successful projects. In this aspect, differentiation among the analysed institution is also dispersive. The next aspect of the positioning of institutions in the sphere of startup acceleration and incubation is represented by capitalization. There was found no homogeneous situation in relation to this indicator among the analysed enterprises. The level of capitalization in the selection of the analysed enterprises is quite differentiated. Thus, since 2005 the total market capitalization of all companies of YC, which funded 1,430 companies and almost 3,500 founders, makes more than 5 billion dollars. SparkLabs has insignificant capitalization in comparison with the above-stated institution, which makes 1.2 billion. However, SparkLabs is quite a typical mechanism of positioning, which is reflected in the following elements: they invest up to 40,000 dollars in all startups in exchange for up to $6 \%$ of shares in every startup. This share is subject to negotiations depending on the amount and investment status of project launch; in the course of the acceleration program startups take part in our training sessions, where they have a chance to learn and communicate with the well-known Korean and international entrepreneurs. Besides, during office work startups can have feedback from general partners of SparkLabs; SparkLabs provides free-of-charge office premises in MARU180 centre for the startup in Korea and benefits for the amount over 900,000 Dollars, starting from cloud services, legal advisers and SendGrid. Besides, SparkLabs is the first Korean member of Global Accelerator Network (GAN), which means that our startups also can be provided with various benefits of GAN (Main statistics of worldwide Seed Accelerators (2017)). For today, Techstars Ventures have venture capital in the amount of 400 million dollars. 


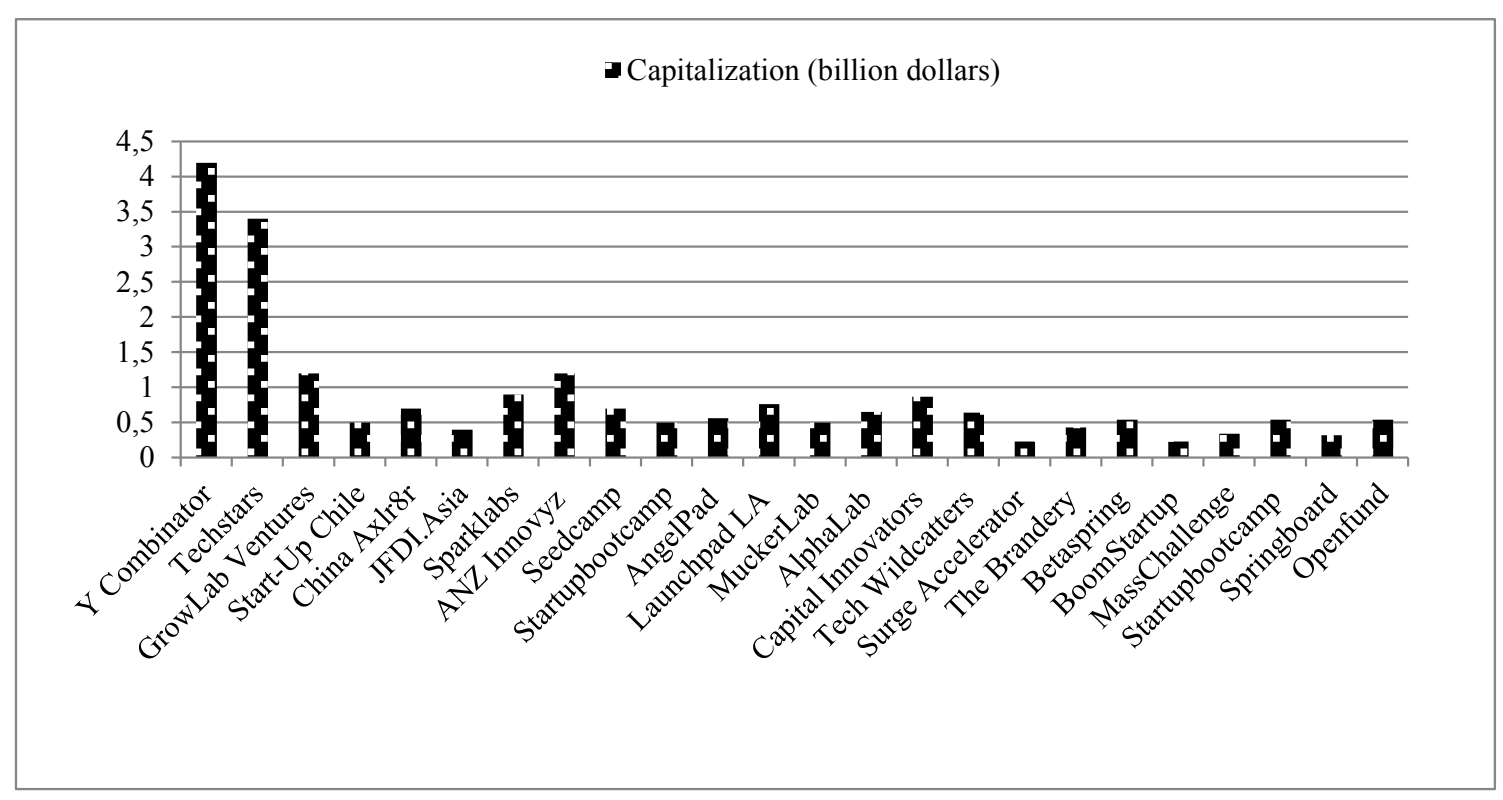

Figure 1. The market capitalization of the analysed enterprises specialized in startup acceleration and incubation in 2017

The Fund Techstars Ventures 2017 also has 265 million US dollars and now they invest the amount of 150 million US dollars from the third fund (according to their website). They invest in the companies-accelerators, established by graduates-accelerators. Figure 1 shows the total market capitalization of the analysed enterprises, specialized in startup acceleration and incubation in 2017. We can see quite significant differentiation among the analysed enterprises, specialized in startup acceleration and incubation in terms of market capitalization. Thus, Y Combinator and Techstars have the determinant amounts of capitalization that, in our opinion, is caused by the fact that they were the first institutions of that type. In general, as we can see from the author's analysis, startup accelerators of the USA prevail on the market for innovations and startups. For instance, among the analysed enterprises by the level of capitalization, the European and Asian enterprises have on average from 200 to 500 million dollars. However, startup accelerators from the USA have higher indicators on account of running certain enterprises after their launch. The last indicator within the framework of the author's analysis is differentiation by the number of sectoral areas under consideration. It should be noted that the emphasis in today's general trends of venture investment is laid on sectoral specialization.

Although, among the analysed institutions, we can see quite insignificant differentiation of project, which they admit (not exceeding 8 projects). At the same time, the basic today's trend is an enhancement of the role of the enterprises, specialized in startup incubation and acceleration. Figure 2 shows the general results of cluster analysis related to approaches in the positioning of certain institutes of startup acceleration and incubation in 2017. Using this method we have obtained a hierarchic structure of clusters with the above-stated characteristics, which allows identifying homogeneous formations - "clusters". As we can see in Figure 2, three cluster formations can be identified at the distance level from 2.5 to 5.10 institutions, which undoubtedly occupy a significant segment on the global market, have grouped into cluster No. 1: Start-Up Chile, China Axelerator, FDI.Asia, Seedcamp, BoomStartup, GrowLab Ventures, Betaspring, AngelPad, The Brandery, Springboard.

The peculiar features of institutions of the first cluster, distinctive from the other cluster formations, are represented, first of all, by their geographic location in the developing countries. Modern characteristics of institutions of this cluster consist in the insufficient infrastructure, which is demonstrated by relatively low indicators of political and economic stability, Ease of Doing Business, costs on legal proceedings and high inflation processes. The above-listed aspects, jointly with a certain outflow of high skilled personnel, create a precedent when the indicator of total amount of registered projects (\% from the number of applications) is much higher than in the second and third clusters. Thus, for instance, Start-Up Chile (SUP) is a typical representative of the first cluster Start-Up Chile (SUP). It is generally available startup accelerator, created by the Chilean government for high-capacity entrepreneurs to launch their startups and use Chile as a basis. As a rule, projects raise $90 \%$ of the total amount of costs on program, as well as by the way of reimbursing the costs or as advance payment. However, project startup should provide $10 \%$ of the rest of money. Chilean applicants may submit an application for additional 10 million of Chilean peso if they live abroad and obtained Master's Degree from a leading foreign university. Although, $10 \%$ of share in the project is the highest indicator among the analysed 


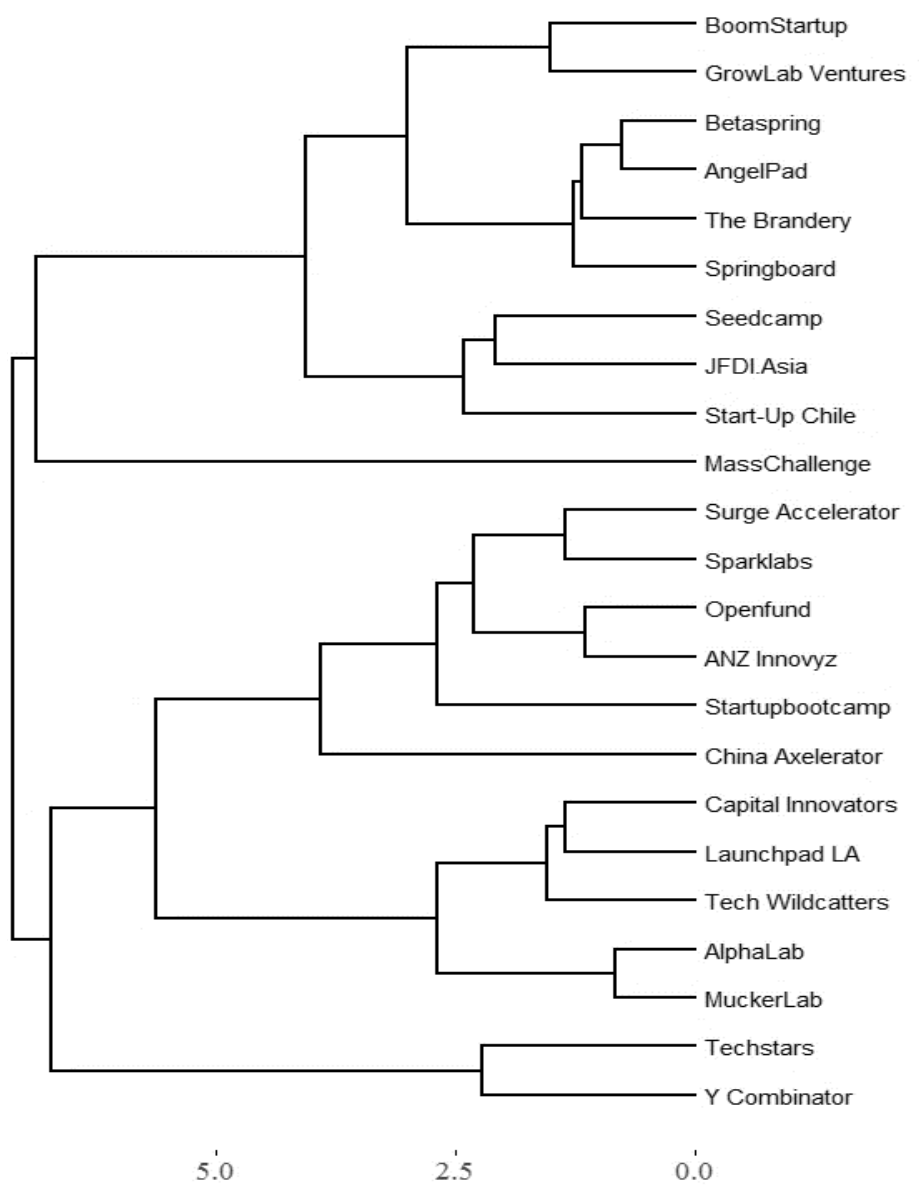

Figure 2. Basic characteristics of approaches in the positioning of certain international institutions of startup acceleration and incubation in 2017

clusters. Y Combinator and Techstars are two institutions, which today have the largest audience of investors and startups, which have involved or wish to get involved in venture investment, have grouped in the cluster No. 2. First of all, basic characteristics of the enterprises of the second cluster are represented by the amount of initial investment, which is much more than in the first and third clusters. Such a context is possible on account of considerable capitalization. These two institutions are the first formations of this type. This, Y Combinator has been founded in 2005. From 2005 to 2008 one program had been conducted in Cambridge, Massachusetts, and another one had been conducted in Mountain-View, California. In January, 2009 Y Combinator announced that Cambridge program would be closed and all further programs would be conducted in the Silicon Valley. In 2009 Sequoia Capital has carried out investment round in the amount of 2 million US dollars that were invested in Y Combinator. It will enable this company to invest in about 60 companies per year, in contrast to their previous investment in 40 companies per year (Main statistics of worldwide Seed Accelerators (2017). Techsters also has the characteristics, similar to Y Combinator. Sturtaps have an opportunity to submit an application to take part in the program of Techstars, and their viability will be evaluated by the Managing Director of the program that they apply for as well as by the Screening Committee, consisting of diverse members of Techstars network. In exchange to $6 \%$ of ordinary shares, every company, admitted by Techstars, receives 20,000 dollars; plus a convertible note in the amount of 100,000 dollars, access to Techstars network for a lifetime, more than one million dollars of benefits and three-month program of accelerators, which is conducted in three stages (Main statistics of worldwide Seed Accelerators (2017)).

Cluster No. 3 contains a group of three institutions, which, in contrast to the others, have higher specialization and also put emphasis on their positioning in less number of projects, which are admitted to acceleration program. The third cluster of the institution is characterized by a less preparatory period. Thus, the analysed enterprises of the first and second cluster have 90 days of acceleration program in average, although the enterprises of the third cluster conduct the acceleration program during 70 days (Main statistics of worldwide Seed Accelerators (2017)).

One of the typical representatives of the third cluster is AlphaLab - national startup accelerator, founded in 2008. As a chartered member of the Global Accelerator 


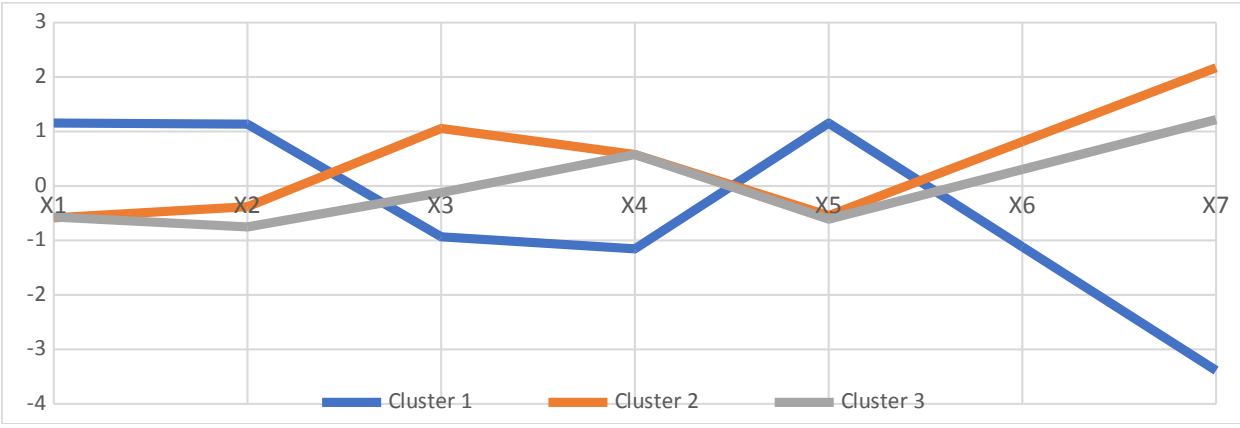

Figure 3. The configuration of the distances of cluster formations using the method of $\mathrm{K}$-means in approaches to startup acceleration and incubation process

Network (GAN) and one of the first ten accelerators of the entire world, AlphaLab has invested and collaborated with 113 companies, including 12 acquired companies. AlphaLab network consists of leading entrepreneurs, investors and mentors in the Pittsburg region and other countries. Success stories, related to startups in the highly-developed companies, include NoWait (acquired by Yelp), Jazz, Black Locus (acquired by Home Depot), Shoefitr (acquired by Amazon) and The Zebra. AlphaLab is also a part on the startup stage of a seed fund, which has invested over 50 million UD dollars in more than 160 companies, which jointly raised over 1.3 billion dollars. These companies include ModCloth, 4Moms, Civic Science, mobile technologies (acquired by Facebook Facebook) and ShowClix. In general, analysing structural elements of the enterprises of the third cluster, it should be noted that, according to their characteristics, these enterprises have a more selective approach to consideration and acceleration, as well as incubation of new projects. In order to compare the difference in approaches to the above-stated process, we have calculated a configuration of the distances of cluster formations using the method of к-means (see Figure 3).

Figure 3 shows that, despite the fact that all clusters have quite different approaches to positioning, the total financial return in all the analysed clusters is quite similar.

\section{Conclusion}

Therefore, in the course of clusterization of the enterprises, specialized in the acceleration of scientific and technological entrepreneurship, we have justified the indicators, which demonstrate the key system parameters of the positioning of the largest ones by capitalization and other quantitative and qualitative indicators. First of all, it is quantitative and qualitative methods and forms of startup investment, which make it possible to optimize and enhance the effectiveness of the startup phase of acceleration or incubation. Secondly, it is the quantitative characteristics of share in the project (\%), which enables us to determine the extent of the developers' readiness to alienate a certain part of the project. Thirdly, it is a total amount of the registered projects (\% of the number of applications), which determines general principles and methods for selection and its impact on final results. Fourthly, it is a number of successful projects. This indicator clearly determines which projects have a capacity for effective exit and positioning. Fifthly, it is an amount of time, spent on acceleration, which enables us to understand the difference between the existing training programs and to single out effective elements. Sixthly, it is the level of capitalization, which makes it possible to justify the impact of the amount of capitalization on final incomes. Seventhly, it is a quantity of sectoral areas under consideration. This indicator is also highly relevant in terms of understanding of the existing trends in effectiveness of organizing the process of acceleration or incubation. Justification and calculation of the above-stated indicators enabled us to conduct cluster analysis, using the approaches to functioning of the enterprises, specialized in acceleration and incubation of venture businesses, as well as to develop the following classification: accelerators and incubators-followers, which have a distinctive feature of insufficient infrastructure, demonstrated by relatively low indicators of political and economic stability, Ease of Doing Business and, as a result, they are characterized by significant share in projects, undergoing acceleration or incubation, which is much higher than in other clusters; specific accelerators and incubators, which have larger specialization, and they also lay emphasis in their positioning on the higher level of readiness of the projects, which are admitted to the acceleration program along with a very slight period of acceleration.

Based on the developed configuration of the distances of cluster formations using the method of $\mathrm{K}$-means in approached-to-startup acceleration and incubation process, we have found out that, despite the fact that all clusters have quite different approaches to positioning, the total financial return in all of the analysed clusters is quite similar. Therefore, further analysis of the most effective accelerators and incubators is of considerable interest in terms of finding the best practices in the area of venture business acceleration. 


\section{References:}

Ganamotse, G. N., Samuelsson, M., Abankwah, R. M., Anthony, T., Mphela, T. (2017). The Emerging Properties of Business Accelerators: The Case of Botswana, Namibia and Uganda Global Business Labs. Journal of Entrepreneurship and Innovation in Emerging Economies, 3(1), 16-40.

Dellermann, D., Lipusch, N., Ebel, P., Leimeister, J. M. (2017). Building Your IoT Ecosystem: Proposing the Hybrid Intelligence Accelerator.

DaSilva, C. M., Gurtner, P. (2017, January). Accelerators: an Assessment of Acceleration Models. In Academy of Management Proceedings (vol. 2017, no. 1, p. 12198). Academy of Management.

Gonzalez-Uribe, J., Leatherbee, M. (2017). The effects of business accelerators on venture performance: Evidence from start-up chile. The Review of Financial Studies, 31(4), 1566-1603.

Shane, S., Nicolaou, N. (2017). Exploring the changing institutions of early-stage finance. Journal of Institutional Economics, 1-17.

Yakowicz, W. (n.d.). The 15 Best Startup Accelerators in the U.S. Retrieved June 13, 2018, from: https://www.inc.com/ will-yakowicz/the-15-best-startup-accelerators-in-the-us.html

Graham, Paul (January 2009). "California Year-Round”. Y Combinator. Retrieved June 13, 2018, from: http://old.ycombinator.com/ycca.html

Manalac, Kat (2016). "YC Office Hours in 11 Countries This Fall”. Y Combinator Posthaven. Retrieved June 13, 2018, from: https://blog.ycombinator.com/yc-office-hours-in-11-countries-this-fall

“Techstars Alumni Companies”. Techstars (2017). Retrieved June 13, 2018, from: https://www.techstars.com/ companies/

The BIC - Business and Innovation Centre (2017). Retrieved June 13, 2018, from: http://bicminho.eu/what-isa-eu-bic/?lang=en

Main statistics of worldwide Seed Accelerators (2017). Retrieved June 13, 2018, from: https://www.seed-db.com/ accelerators

Sazonets, I. L., Gladchenko, A. Y. (2011). Dialectical unity of globalization and regionalization processes within world economy. Actual problems of economics, (126), 66-72. 